Production and Health Paper No. 172. Rome, Italy.

Gomez, A.K. and A. A. Gomez. 1984. Statistical Procedures for Agricultural Research. John Wiley \& Sons. New York, USA.

Hesham, A., Yasser, M., Hanafi A. , Radwan and Tarek H., 2015. Redesign and Manufacture an Impact Crusher Hammer Mill Using Advanced Iron Casting. Global journal of advanced research. Vol-2, Issue-7 PP. 11961209

HOQUE M., SOKHANSANJ S., NAIMI L, BI X AND LIM J (2007). Review and Analysis of Performance and Productivity of Size Reduction Equipment for Fibrous Materials. ASABE paper no: 076164 St Joseph, Mich., pp2-6.

Nikolov, S. (2004). Modeling and simulation of particle breakage in impact crusher. International journal of mineral processing $74 \mathrm{~s}: 219-225$.

Wiki love Africa, 2017. Agriculture in Ethiopia (Available at https://en.wikipedia.org/wiki/Agriculture_in_Ethiopia) 


\title{
Mathematical Model Describing Effect of S.Cerella on Paddy in the Environmental Ecosystem
}

\author{
Rakesh Yadav \\ Associate Professor, Department of mathematics, School of Chemical Engineering \& Physical Sciences \\ Priyanka \\ Student, Department of mathematics, School of Chemical Engineering \& Physical Sciences
}

\begin{abstract}
In this paper we will establish a mathematical model with the help of second order differential equations by assuming that the rate of change of percentage germination loss with respect to grain infestation is proportional to germination loss. We have selected entomological data for our problem to be in the paper. The model is useful for better management of storage of grains and it will reduce the storage losses of grains under the consideration of various parameters like moisture, humidity etc.
\end{abstract}

Keywords: Germination loss , Infestation loss, Grains, Storage system etc.

DOI: $10.7176 / \mathrm{CPER} / 61-03$

Publication date: April $30^{\text {th }} 2019$

1. Introduction: In agriculture departments of various universities of World, where agricultural researches are going on, plentiful statistics are available to provide a basis for various analytical study. As a matter of fact, they are not of as much use as it ought to be because they are fragmentary and inconclusive. For this model we have gone through the research work of [1] Kapoor,J.N, [2] Pandey.V, [3] Prkash .A , [4]. Singh R.A and Rizvi. S.M , [5] Singh V , [6] Ashamo M. O et al. Through mathematical models we give them systematic order to gain better insight into the problem for data has been collected, so that data may prove more useful for agricultural production. To have a clear and complete picture and the results of various problems consideration data are required for the formation of mathematical models. The storage condition which gives the validity and vigour of the seeds and various type of losses as a result of physiological and biochemical changes, differs considerably under the different storage system. In stores, grains absorb moisture because of humidity and get infected, resulting into development of insect population. Besides, these are perspiration or metabolic changes, depletion of foods reserves such as carbohydrates, proteins and oil, genetic changes and changes in membrane permeability. All these factors cause huge losses during storage. Therefore, it seems essential to study the effects of these factors and establish their relationship through modelling for better management and forecasting.

Due to high humidity harvested and processed paddy retains high moisture content, which predisposes grains for considerable storage losses every year. Paddy in storage is damaged by a dozen insects but only a few viz. angoumsis grain moth, Sitotroga Cerealella oliv etc are most harmful insects to damage grains. Pest status of an insect in rice storage period and local climatic conditions. A biotic environment like the grain moisture, humidity temperature, light and type of storage structure mentioned earlier and the storage losses due to insects. Losses may be quantitative and qualitative, i.e. reduced germination and contamination with mycotoxins. We have discussed some factors affecting the storage ecosystem, like atmosphere humidity and grain moisture content, temperature, light, season food etc.

We will establish a Mathematical model with the help of second order differential equations by assuming that the rate of change of percentage germination loss with respect to grain infestation is proportional to germination loss.

\section{Formulation of the model}

We conducted an experiments at Achrya Narendra Dev Agriculture University,crop research station, Faizabad U.P. we have selected twenty five grams of seed, each of 10 selected varieties ,comprising of 5 grain types were kept in $100 * 25 \mathrm{~mm}$ size preterlised glass specimen tubes, were placed inside the desiciotor with some adult moth and performed the whole experiment under different environment conditions for different periods. We have extracted statistics from the experiments to develop mathematical models by considering two varieties viz. percentage grain infestation and percentage loss in germination.

Losses in grains weight and germination of rice varieties infested by S.Cearelella of 3, 6, and 9 months of duration. 


\begin{tabular}{|c|c|c|c|c|c|}
\hline \multicolumn{3}{|c|}{ \% Grain infestation } & \multicolumn{3}{c|}{ \% Loss in germination } \\
\hline 3 months & 6 months & 9 months & 3 months & 6 months & months \\
\hline 11.5 & 14.9 & 21.4 & 15.2 & 19.4 & 27.3 \\
\hline 4.6 & 7.3 & 7.3 & 9.9 & 18.5 & 21.2 \\
\hline 13.7 & 16.1 & 16.1 & 23.3 & 26.5 & 31.0 \\
\hline 11.5 & 12.1 & 15.1 & 18.9 & 22.7 & 24.5 \\
\hline 3.3 & 5.4 & 9.8 & 8.0 & 10.5 & 16.5 \\
\hline 6.5 & 7.3 & 7.9 & 8.6 & 13.9 & 16.9 \\
\hline 9.9 & 10.5 & 10.0 & 11.8 & 14.2 & 18.5 \\
\hline 10.5 & 10.5 & 13.2 & 15.3 & 17.2 & 10.9 \\
\hline 10.2 & 14.4 & 17.9 & 17.3 & 19.9 & 25.0 \\
\hline 15.5 & 17.7 & 23.5 & 21.4 & 26.2 & 33.0 \\
\hline
\end{tabular}

Figure-1(a)

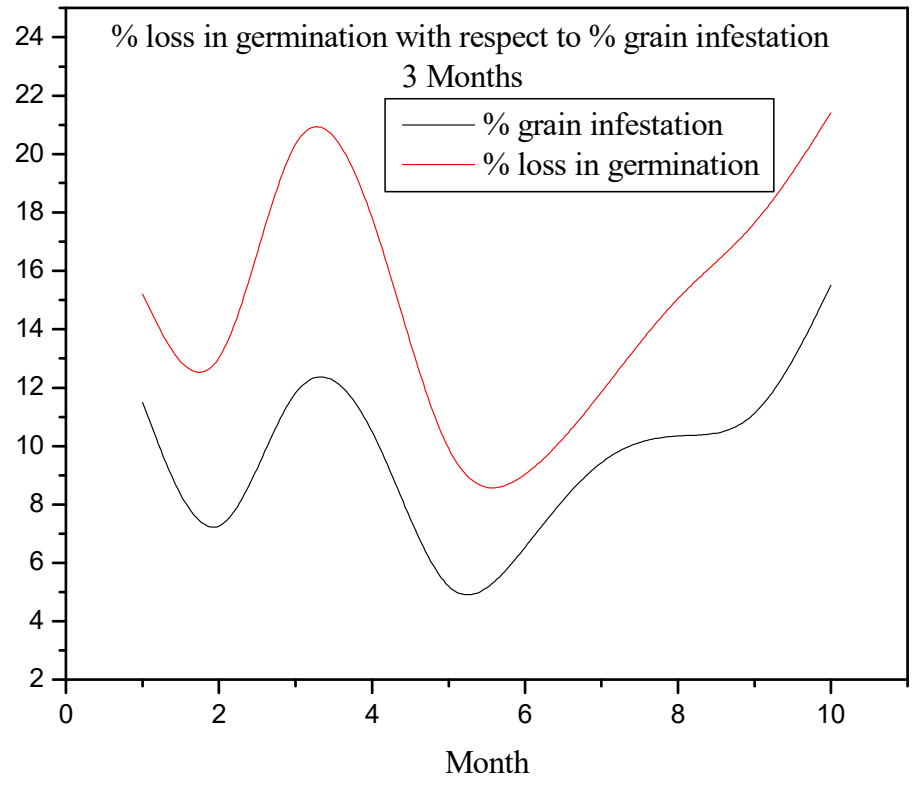

Figure-1(b)

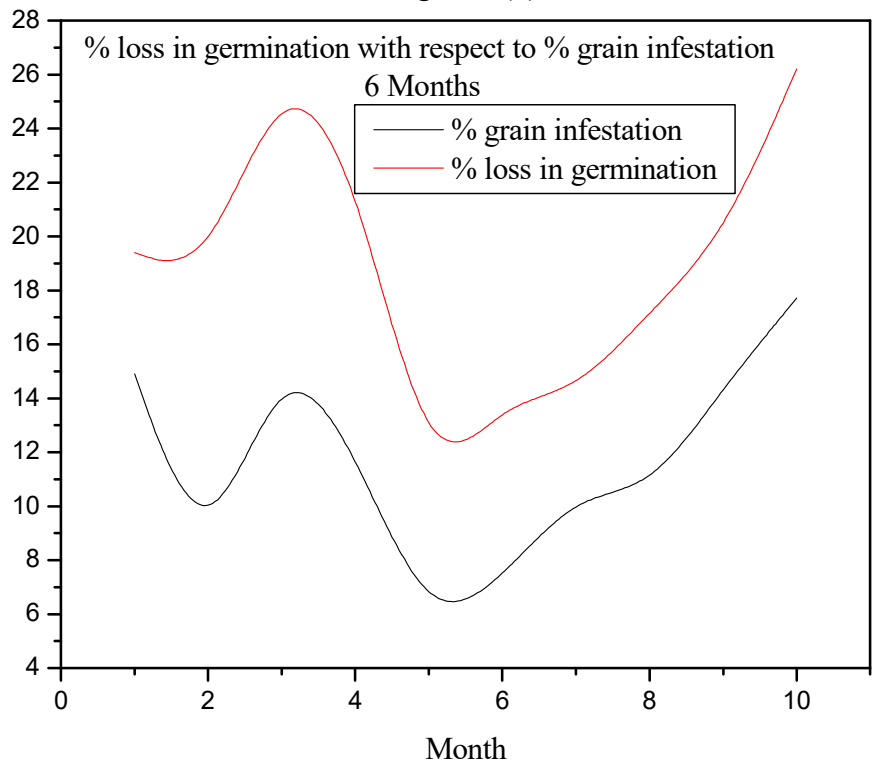


Figure-1(c)

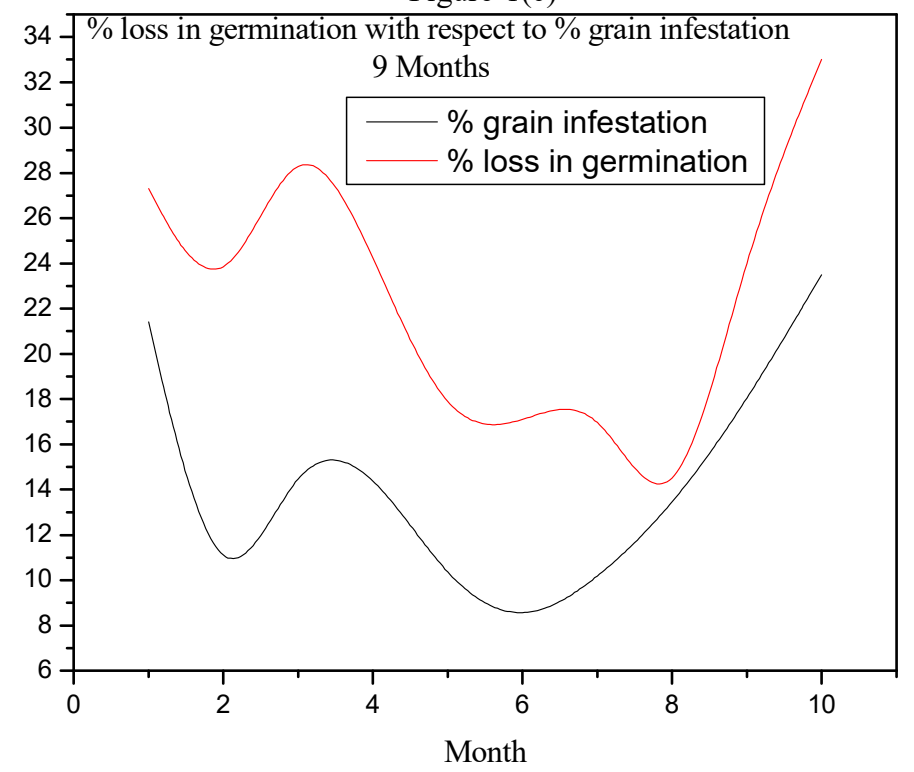

From figures, it evinces that percentage loss in germination value is behaving in oscillatory manner with respect to (kernel) percentage grain infestation. Therefore, it is postulated that percentage germination loss with respect to percentage grain infestation obeys a law where solution shows the oscillatory nature. Before trying any law to mould this situation we first idealise the experimental data to the extent that the idealised data is included most of the original data and some averaged data. The idealisation is required for the reason as follows:

To curve in figure is idealised to give a curve of frequency which shows the nature of oscillation. To obtain observation Percentage loss in germination $\mathrm{Xi}$ are averaged at averaged kernel (grain infestation) for further use.

\begin{tabular}{|c|c|c|c|}
\multicolumn{1}{c|}{} & Average experimental data & \multicolumn{2}{c|}{ Idealised average data } \\
\hline $\begin{array}{c}\text { Kernel } \\
\text { infestation }\end{array}$ & Germination percent loss & $\begin{array}{c}\text { Kernel } \\
\text { infestation }\end{array}$ & $\begin{array}{c}\text { Germination } \\
\text { percent loss }\end{array}$ \\
\hline 75.9 & 20.6 & 16 & 21 \\
\hline 7.4 & 22.0 & 7 & 10 \\
\hline 17.2 & 26.9 & 17 & 27 \\
\hline 18.1 & 24.1 & 19 & 28 \\
\hline 6.1 & 22.0 & 6 & 12 \\
\hline 7.2 & 11.6 & 7 & 17 \\
\hline 10.1 & 14.8 & 10 & 10 \\
\hline 11.4 & 14.4 & 11 & 21 \\
\hline 14.1 & 20.7 & 14 & 27 \\
\hline 18.9 & 26.8 & 19 & \\
\hline
\end{tabular}

Also we have omitted one data of germination losses $X_{i}$ at grain infestation $Y_{i}$. Simply because they are not behaving according to the general trends of the other data, may be due to some other variables presented at the time of recording the data but they are not present here. Other observations of the table are as the same five in table 2. According to the follow up of the idealised data and corresponding curve.

It is postulated that the rate of percentage germination loss ' $Z$ ' with respect to grain infestation ' $I$ ' is proportional to the $\mathrm{Z}$ i.e.

$$
\begin{gathered}
\frac{d^{2} Z}{d I^{2}} \alpha Z \\
\frac{d^{2} Z}{d I^{2}}=-\omega^{2} Z
\end{gathered}
$$

Where $\omega^{2}$ is constant of proportionality.

\subsection{Discussion and solution:}

Solution of equation (1) is given by 


$$
Z=C_{1} \cos \omega \mathrm{I}+\mathrm{C}_{2} \sin \omega \mathrm{I}
$$

Where $C_{1}$ and $C_{2}$ are arbitrary constant.

An equivalent expression for the solution of equation (1) is

$$
Z=A \sin (\omega I+\phi)
$$

Where $\sin (\omega I+\phi)=\sin \omega I \cos \phi+\cos \omega I \sin \phi$

Using equation (4) in equation (3) we arrive at

$$
Z=A \sin \omega I \cos \phi+A \cos \omega I \sin \phi
$$

In view of equations (3) and (5) we get,

$$
\begin{aligned}
& C_{1}=A \sin \phi \\
& C_{2}=A \cos \phi
\end{aligned}
$$

Which evidently provide us

$$
A^{2}=C_{1}^{2}+C_{2}^{2} \text { and } \phi=\tan ^{-1}\left(C_{1} / C_{2}\right)
$$

Where $\mathrm{A}$ is called amplitude of oscillation and the oscillation is $(\omega I+\phi)$ Phase angle is $\phi$

If we start from maximum point i.e. $\phi=\frac{\pi}{2}$ in equation (5) reduces to

$$
Z=A \cos \omega I
$$

Where $\mathrm{w}$ is the circular frequency and equation (6) and (7) reduces to

$$
C_{1}=A, C_{2}=0
$$

$\omega$ is also expressed in terms of period as

$$
\omega=\frac{2 \pi}{T}
$$

Where $\mathrm{T}$ is the period of oscillation or distance between two points.

Using equation (8) and (9), we get,

$$
\begin{gathered}
p=A \cos \left(\frac{2 \pi}{T}\right) l--------(10) \\
\text { At } \phi=\frac{\pi}{2}
\end{gathered}
$$

\begin{tabular}{|c|c|c|c|c|c|}
\hline $\mathrm{x}$ & $\mathrm{y}$ & $\mathrm{u}$ & $\mathrm{v}$ & uv & $u^{2}$ \\
\hline 16 & 21 & +6 & 1 & -6 & 36 \\
\hline 7 & 10 & -3 & -10 & 30 & 9 \\
\hline 17 & 27 & 7 & 7 & 49 & 49 \\
\hline 19 & 28 & 9 & 8 & 72 & 81 \\
\hline 6 & 12 & -4 & -8 & 32 & 16 \\
\hline 7 & 17 & -3 & -3 & 9 & 9 \\
\hline 10 & 15 & 0 & -5 & 0 & 0 \\
\hline 11 & 10 & 1 & -10 & -10 & 1 \\
\hline 14 & 21 & 3 & 1 & 3 & 9 \\
\hline & & $\sum u=16$ & $\sum v=19$ & $\sum u v=198$ & $\sum u^{2}=209$ \\
\hline
\end{tabular}

We claim that equation (10) in the model representing the data given in table. To justify the claim we proceed to test the model.

Equation (10) is expected to generate data represented by fig (2). It is evident that equation (10) represents a wave equation where the displacement curve is represented with respect to a line of symmetry which we term as a "line of best fit" of the data table, so fitting a line $y=m x+c$, to the data we obtain the equation.

$$
y=0.90 x+11.5-------(11)
$$

the inclination of line is 0.90 which gives remarkable effect i.e. germination value of grains is directly depend upon percent grain infestation.

Let, $u=x-10, v=y-20$ 


$$
\begin{aligned}
& x=10+(16 / 9)=11.7 \\
& y=20+(19 / 9)=22.1 \\
b_{y x}= & \frac{(9 \times 198)-(16 \times 19)}{(9 \times 209)-(16)^{2}} \\
b_{y x}= & 0.90
\end{aligned}
$$

Hence regression line is given by

$$
\begin{aligned}
& y-22.1=0.90(x-11.7) \\
& y=0.9 x+11.4
\end{aligned}
$$

\section{Conclusion}

We conclude from this model that Infestation by S.Cerealella inflected considerable damage to impact significant varieties in germination between different storage periods. As insect infestation increased progressively with the storage period, germination decreased following more or less similar trend. Insect infestation is dependent upon the number of insect present in the store. Also increase in population of insect depends upon the environmental factors i.e. environmental ecosystem. This mathematical model lays emphasis on the role insect infestation during storage of grains, in reducing germination which proves its efficiency in itself.

\section{References:}

[1] Kapoor,J.N , Mathematical Modelling.

[2] Pandey.V (2005) and "Comparative resistance of paddy varieties to Sitotroga Cerelella oliver". Bull. Ent. Vol. 21; 132-134.

[3] Prkash .A (2011) and "Population fluctuations of insect pests in stored paddy under natural and controlled condition”. Oryza Vol. 18; 90-92.

[4]. Singh R.A and Rizvi. S.M.(2015) “ Influence of certain paddy grain characters on in the infestation of S.C oliv. In storage.” J. App. Zool. International Journal of Horticulture, 2018, Vol. 8, No. 9 doi: 10.5376/ijh 2018.2(1); 39-42.

[5].Singh V.R Parameters of the Predator, Geocoris Ochropterus Fieber. (Hemiptera: Geocoridae), Fed on Sitotroga cerealella (Olivier) eggs.” Egyptian Journal of Biological Pest Control, 2017,Vol. 27 Issue 2, p189-194. 6p.

[6] Ashamo M. O, Ogungbite O. C., Adetogo T. A."Insecticidal Potency of Newbouldia laevis Oil Extracts against Sitrotoga cerealella , An Important Pest of Paddy Rice.” International Journal of Horticulture, Vol. 8, No. 9 doi: 10.5376/ijh.2018. 


\title{
Preparation of Indigenous Copper Oxide Nanoparticles for Desulfurization of Natural Gas
}

\author{
A.Qudoos $^{1} \quad$ S.Farman $^{1} \quad$ Shaheen Aziz $^{1} \quad$ Sirajuddin $^{2}$ \\ 1.Department of Chemical Engineering, Mehran University of Engineering \& Technology, Jamshoro-76080 \\ Pakistan \\ 2.National Centre of Excellence in Analytical Chemistry, University of Sindh, Jamshoro-76080 Pakistan
}

\begin{abstract}
Nanotechnology has attained significant concern in the field of Environmental Protection, Health Risk Energy, Material Science, Biotechnology, Information Technology, Pharmaceuticals, Tissue Engineering, Cosmetics, Food and Agriculture, and others. In this research the preparation of indigenous copper oxide Nanoparticles $\left(\mathrm{Cu}_{2} \mathrm{O}\right.$ NPs) were prepared by the bottom up approach in the presence of Sodium do Decyl Sulfate (SDS). Material properties of Copper oxide NPs such as Scanning Electron Microscopy (SEM), X-ray Diffraction (XRD) and Fourier Transforms Infrared (FTIR) spectroscopy were also studied. The SEM demonstrated the surface of indigenous Copper Oxide NPs was non-agglomerated powders with irregular ball resembling particles. The X-ray Diffraction (XRD) analysis explained that the $\mathrm{Cu}_{2} \mathrm{O}$ NPs were highly crystalline in nature with average size was found to be $3.5 \mathrm{~nm}$ ranging from 2 to $5 \mathrm{~nm}$ were recorded by the help of scherrer formula. The Fourier transforms infrared (FTIR) spectroscopy described the carbonyl group are responsible for formation of stable indigenous $\mathrm{Cu}_{2} \mathrm{O}$ NPs. These stable Indigenous cuprous oxide nanoparticles would be applied for the desulfurization of natural Gas separation purpose.
\end{abstract}

Keywords: Indigenous, Copper oxide nanoparticles $\left(\mathrm{Cu}_{2} \mathrm{O}\right.$ NPs), chemical reduction, SDS, morphology, desulfurization and natural gas.

DOI: $10.7176 / \mathrm{CPER} / 61-04$

Publication date: April $30^{\text {th }} 2019$

\section{Introduction}

Nanotechnology is integrative field that covers diversified knowledge about the preparation, design and engineering of Nano-sized equipments and materials [2]. Ancient Historic evolution of nanotechnology is defined by Daniel and Astruc. The begging of 21 st century rapid progress in the field of Nanotechnology has initiated with establishment of National Nanotechnology Initiative [3]. It is an engineering of manufacturing very small Nano-sized 1 particles, materials and devices [4]. By applying the principles of Nanotechnology, research have developed various indigenous materials at Nano scale having at least one side $<100 \mathrm{~nm}$ [5]. Nanotechnology is used to improving the various other fields like medicine, chemistry, information technology, many engineering technologies and others to develop the novel Nano-structured indigenous material [6]. Numerous synthesis methods are developed to enhancing the various properties of nanoparticles with low cost [7]. Nanoparticles are generally classified into carbon, organic and Inorganic based, Furthermore inorganic are classified as metal based, metal oxide based. Nearly all metals can be converted in to metal nanoparticles, however metal oxides nanoparticles possess high reactivity and high efficiency [8-10].

Researchers have developed NPs of various metal oxides like $\mathrm{MgO}, \mathrm{Cu}_{2} \mathrm{O}, \mathrm{CuO}, \mathrm{ZnO}, \mathrm{Fe}_{3} \mathrm{O}_{4}, \mathrm{CaO}, \mathrm{TiO}_{2}$, $\mathrm{ZrO}_{2}, \mathrm{CeO}, \mathrm{NiO}, \mathrm{SnO}_{2}, \mathrm{Al}_{2} \mathrm{O}_{3}, \mathrm{CdO}_{3}$ and $\mathrm{Co}_{3} \mathrm{O}_{4}$ through different available techniques [11-14]. With the advancement in the field of nanotechnology, NPs are developed for the removal of impurities from the fuels. NPs of metal oxide has been tested for removal of Sulfur and sulfur compounds from gas due to high surface area, high reactivity i.e, $\mathrm{TiO}_{2}$ has been used for removal of $\mathrm{SO}_{2}$ from gas, $\mathrm{ZnO}$ and Iron oxide used for removal of hydrogen sulfide and other sulfur compounds from gas [14-16].

In this study cuprous oxide nanoparticles were prepared by chemical reduction method and Characterization was done by Scan Electron Microscopy (SEM), Fourier Transforms Infrared and spectroscopy (FTIR). These indigenous cuprous oxide nanoparticles will be used for the Desulfurization of Natural Gas using Indigenous cuprous oxide nanoparticles.

\section{Experimental Setup:}

\subsection{Materials and reagents}

All chemicals used were of analytical grade and used without further purification by employing pure Milli-Q water as the preparation medium. Copper Sulfate $\left(\mathrm{CuO}_{4} \mathrm{~S} .5 \mathrm{H}_{2} \mathrm{O}\right)$, Sodium dodecyl Sulfate $\left(\mathrm{C}_{12} \mathrm{H}_{25} \mathrm{NaO}_{4} \mathrm{~S}\right)$, Ascorbic acid $\left(\mathrm{C}_{6} \mathrm{H}_{8} \mathrm{O}_{6}\right)$ and Sodium hydroxide $(\mathrm{NaOH})$ were purchased from E.Merck.

\subsection{Instrumentation Setup}

The Ultra-visible spectroscopy model (Lambda 356 of Perkin-Elmer) initially used for investigation of 
indigenous $\mathrm{Cu}_{2} \mathrm{O}$ NPs by showing Surface Plasmon Resonance (SPR) band within the UV-visible range of 200$800 \mathrm{~nm}$ [17]. The X-ray Diffraction (D-8 Bruker) one of the best non-destructive techniques used for the phase purity and crystalline patterns confirmation of indigenous $\mathrm{Cu}_{2} \mathrm{O}$ NPs and Scanning Electron Microscopy (model JSM-6380LV) used for the morphological characterization of $\mathrm{Cu}_{2} \mathrm{O}$ NPs $[18,19]$. The surface interaction was identified by Fourier transforms infrared (FTIR) spectroscopy (Nicolet 5700 of Thermo).

\subsection{Preparation procedure of indigenous $\mathrm{Cu}_{2} \mathrm{O}$ NPs}

Aqueous solution of Sodium dodecyl suphate was prepared by dissolving $1.13 \mathrm{~g}$ of Sodium dodecyl sulfate in distilled water with constant stirring for $15 \mathrm{~min}$. Pre-prepared of aqueous solution of 0.1M Copper Sulfate was added into the SDS solution under uniform stirring and then aqueous solution of $0.1 \mathrm{M}$ Ascorbic Acid was added instantly. $1 \mathrm{M}$ Sodium Hydroxide solution was used to attain the $9 \mathrm{pH}$ value of the mixture. Prepared mixture was placed at $90^{\circ} \mathrm{C}$ for 2 hours. Solution was left over 1 night and then washed the distilled water and ethanol for removing inorganic and organic impurities and dried at room temperature. Finally we obtained greenish powder product and storage it for characterization purpose.

\section{Results and Discussions}

\subsection{Scanning Electron Microscopy (SEM) Study}

The surface characterization of indigenous $\mathrm{Cu}_{2} \mathrm{O}$ NPs was done by Scanning Electron Microscopy (SEM). The formation of non-agglomerated powders with irregular ball like particles were formed as shown in Figure 1(a, b)and also with showed that the aggregated mostly round shape structure of $\mathrm{Cu}_{2} \mathrm{O} N P s$.
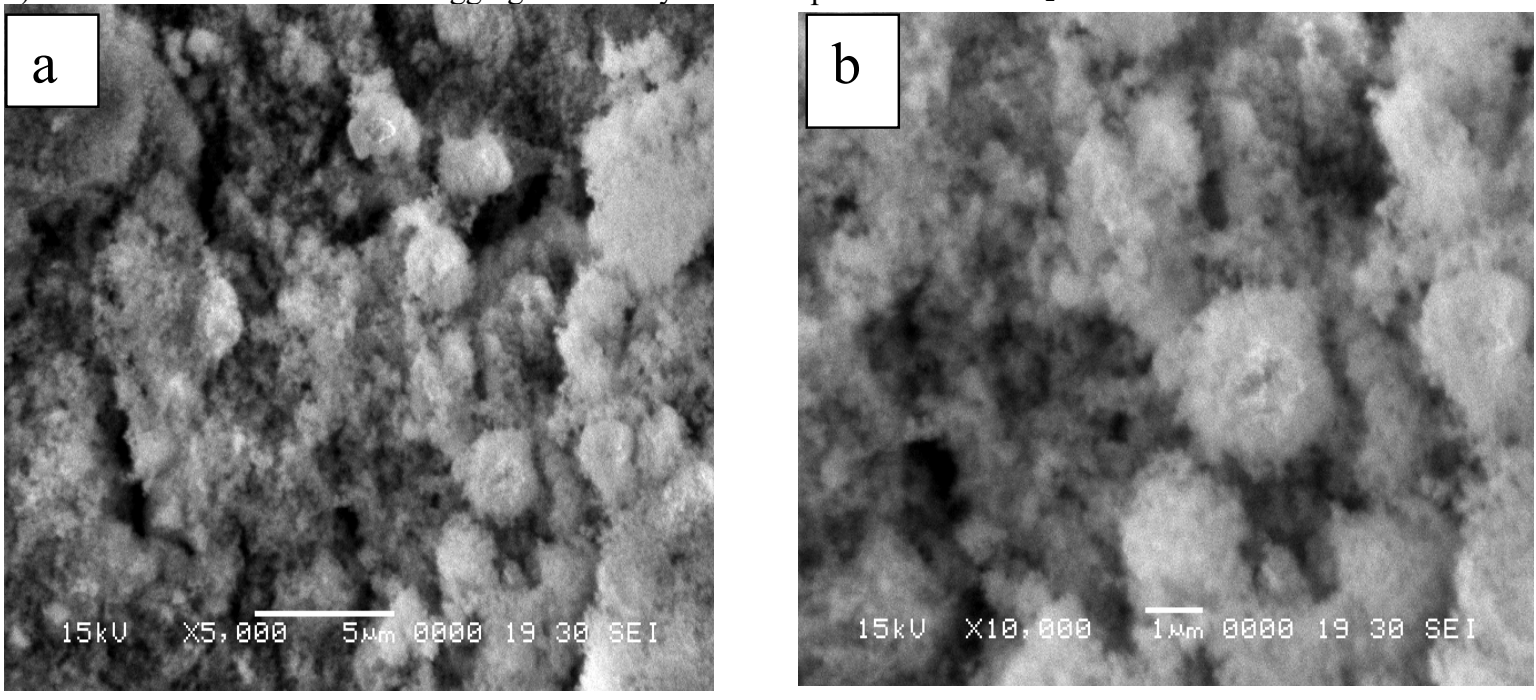

Figure 1: SEM images (a and $b$ ) of indigenous cuprous oxide nanoparticles

\subsection{X-ray diffractometry (XRD) Study}

The X-ray diffraction (XRD) analysis used for the phase purity and crystalline structure of indigenous $\mathrm{Cu}_{2} \mathrm{O}$ NPs, as represented in Figure 2. The XRD spectrum clearly represents five major peaks with miller indexed peak (110), (111), (200), (220) and (311) of $\mathrm{Cu}_{2} \mathrm{O}$. On the contrary, there are no extra peaks of copper and $\mathrm{CuO}$ were observed [20]. The scherrer equation was used for determining the average particles size of ingenious $\mathrm{Cu}_{2} \mathrm{O} \mathrm{NPs}_{\mathrm{s}}$ was found to be $3.5 \mathrm{~nm}$ with particles range from 2 to $5 \mathrm{~nm}$. 


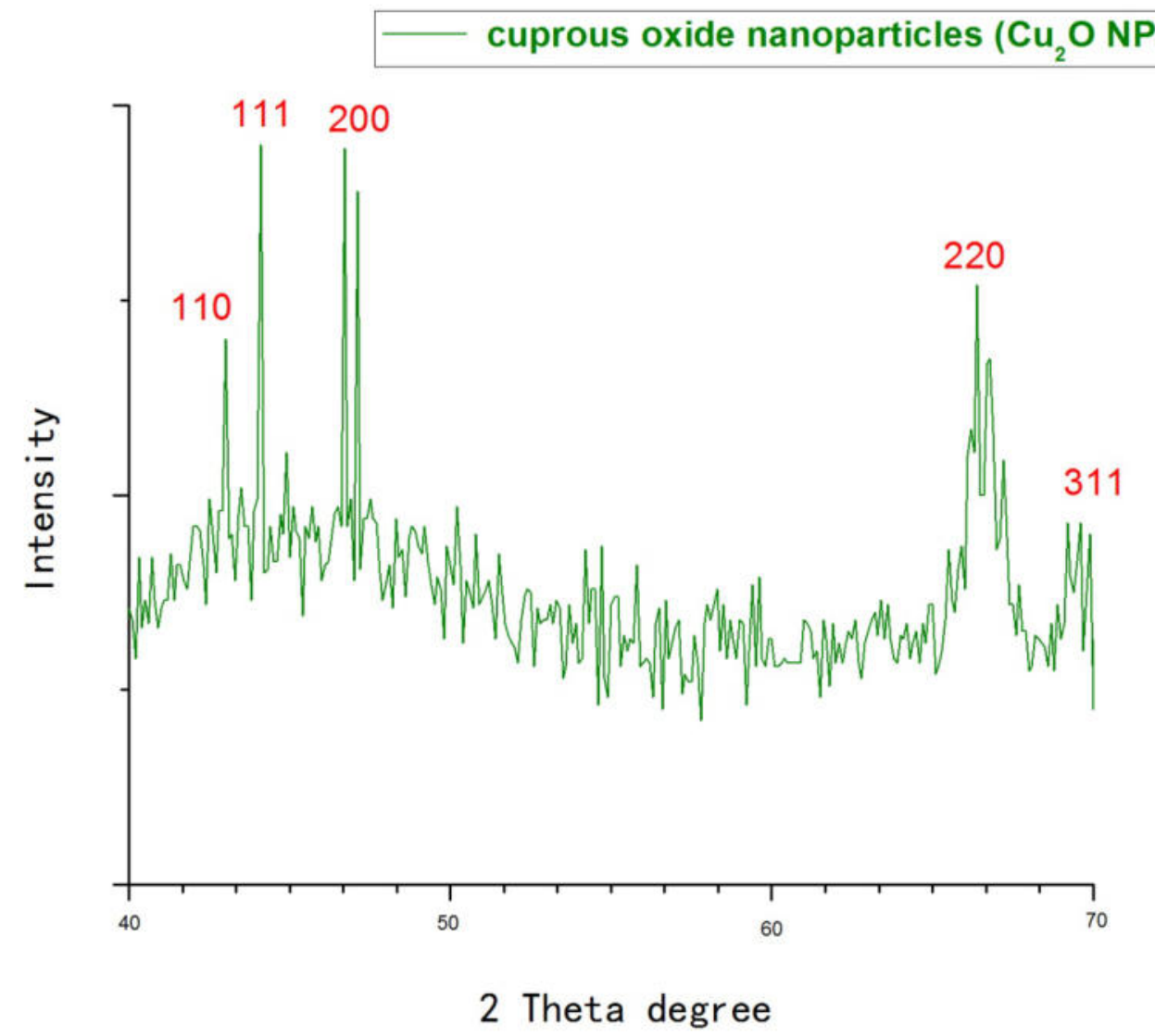

Figure 2: XRD Spectrum of indigenous $\mathrm{Cu}_{2} \mathrm{O}$ NPs

\subsection{Infrared spectroscopy (FTIR) study}

FTIR spectrum of indigenous copper oxide nanoparticles showed various bands that depend upon the vibrational modes[21]. Figure 3 ( $a, b$ and c) represent FTIR spectrum of $\mathrm{Cu}_{2} \mathrm{O}$ NPs, SDS and ascorbic acid. Figure 3a showed that spectrum of $\mathrm{Cu}_{2} \mathrm{O}$ NPs can be interpreted bored and highest intensity of amino group stretching at $3322 \mathrm{~cm}^{-1}$ and bending at $1547 \mathrm{~cm}^{-1}$ as compares to SDS and ascorbic acid in Figure (b and c). The band observed at $1753 \mathrm{~cm}^{-1}$ confirms the presence of carbonyl group $(-\mathrm{C}=\mathrm{O})$ in ascorbic acid clearly disappears in Figure (a). This is the clearly evidence of formation of indigenous $\mathrm{Cu}_{2} \mathrm{O}$ NPs. 

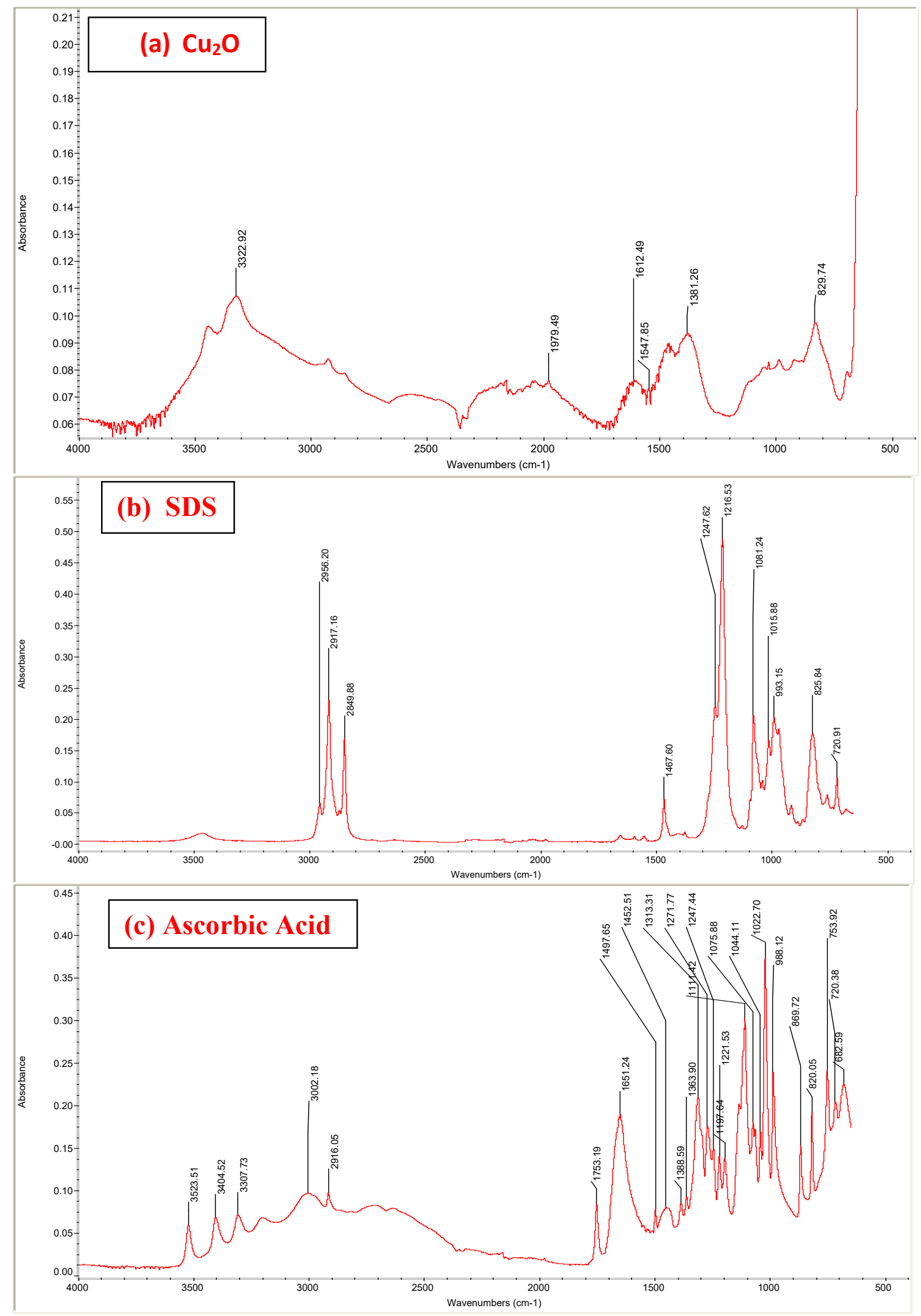

\section{Conclusion}

Figure 3: FTIR spectrum of (a) $\mathrm{Cu}_{2} \mathrm{O}$ NPs and (b) SDS and (c) ascorbic acid 
The stable, economical and simple indigenous cuprous oxide nanoparticles were formed by the simplest chemical reduction method. These indigenous $\mathrm{Cu}_{2} \mathrm{O}$ NPs were successfully characterized by Scanning Electron Microscopy (SEM), X-ray Diffraction (XRD) and Fourier Transforms Infrared spectroscopy (FTIR) spectroscopy and finally that the unique particles size of these $\mathrm{Cu}_{2} \mathrm{O}$ NPs was found to be $3.5 \mathrm{~nm}$ which ranging from 2 to $5 \mathrm{~nm}$ would applicable for the desulfurization of natural Gas separation purpose.

\section{References}

[1] M. Negahdary, H. Heli, Applications of Nanoflowers in Biomedicine, Recent Patents on Nanotechnology, 12 (2018) 22-33.

[2] M. Ferrari, Cancer nanotechnology: opportunities and challenges, Nature reviews cancer, 5 (2005) 161.

[3] M.-C. Daniel, D. Astruc, Gold nanoparticles: assembly, supramolecular chemistry, quantum-size-related properties, and applications toward biology, catalysis, and nanotechnology, Chemical reviews, 104 (2004) 293-346.

[4] P. Zhao, X. Feng, D. Huang, G. Yang, D. Astruc, Basic concepts and recent advances in nitrophenol reduction by gold-and other transition metal nanoparticles, Coordination Chemistry Reviews, 287 (2015) 114-136.

[5] O.C. Farokhzad, R. Langer, Impact of nanotechnology on drug delivery, ACS nano, 3 (2009) 16-20.

[6] I. Khan, K. Saeed, I. Khan, Nanoparticles: Properties, applications and toxicities, Arabian Journal of Chemistry, (2017).

[7] S. Mobasser, A.A. Firoozi, Review of nanotechnology applications in science and engineering, J Civil Eng Urban, 6 (2016) 84-93.

[8] E.J. Cho, H. Holback, K.C. Liu, S.A. Abouelmagd, J. Park, Y. Yeo, Nanoparticle characterization: state of the art, challenges, and emerging technologies, Molecular pharmaceutics, 10 (2013) 2093-2110.

[9] S.A.M. Ealia, M. Saravanakumar, A review on the classification, characterisation, synthesis of nanoparticles and their application, in: IOP Conference Series: Materials Science and Engineering, IOP Publishing, 2017, pp. 032019.

[10] M. Salavati-Niasari, F. Davar, N. Mir, Synthesis and characterization of metallic copper nanoparticles via thermal decomposition, Polyhedron, 27 (2008) 3514-3518.

[11] C.Y. Tai, C.-T. Tai, M.-H. Chang, H.-S. Liu, Synthesis of magnesium hydroxide and oxide nanoparticles using a spinning disk reactor, Industrial \& engineering chemistry research, 46 (2007) 5536-5541.

[12] M. Imran Din, A. Rani, Recent advances in the synthesis and stabilization of nickel and nickel oxide nanoparticles: A green adeptness, International Journal of Analytical Chemistry, 2016 (2016).

[13] M.A. Atieh, H.M. Ibrahim, A.H. Atieh, Platform switching for marginal bone preservation around dental implants: a systematic review and meta-analysis, Journal of periodontology, 81 (2010) 1350-1366.

[14] J. Baltrusaitis, P.M. Jayaweera, V.H. Grassian, Sulfur dioxide adsorption on TiO2 nanoparticles: Influence of particle size, coadsorbates, sample pretreatment, and light on surface speciation and surface coverage, The Journal of Physical Chemistry C, 115 (2010) 492-500.

[15] O. Blatt, M. Helmich, B. Steuten, S. Hardt, D. Bathen, H. Wiggers, Iron Oxide/Polymer-Based Nanocomposite Material for Hydrogen Sulfide Adsorption Applications, Chemical Engineering \& Technology, 37 (2014) 1938-1944.

[16] M. Sekhavatjou, R. Moradi, A. Hosseini Alhashemi, A. Taghinia Hejabi, A new method for sulfur components removal from sour gas through application of zinc and iron oxides nanoparticles, International Journal of Environmental Research, 8 (2014) 273-278.

[17] K. Vijayashree, K.S. Rai, T. Demappa, Synthesis of Nanosized Copper Oxide by Assimilating Microwave Radiation and its Characterizations, Indian Journal of Advances in Chemical Science S1, 6 (2016) 9.

[18] S. Makhloufi, E. Omari, M. Omari, Synthesis, characterization, and electrocatalytic properties of La $0.9 \mathrm{Sr}$ $0.1 \mathrm{Cr} 1-\mathrm{x}$ Co x O 3 perovskite oxides, Journal of the Australian Ceramic Society, 55 (2019) 1-10.

[19] M. Sathishkumar, M. Saroja, V. Venkatachalam, Structural, Morphological and Antimicrobial Activity of pure and Aluminum doped Zinc Sulfide Nanoparticles, Nanoscale Reports, 2 (2019) 17-21.

[20] J. Singh, G. Kaur, M. Rawat, A brief review on synthesis and characterization of copper oxide nanoparticles and its applications, J. Bioelectron. Nanotechnol, 1 (2016).

[21] J.S. Duque, B.M. Madrigal, H. Riascos, Y.P. Avila, Colloidal Metal Oxide Nanoparticles Prepared by Laser Ablation Technique and Their Antibacterial Test, Colloids and Interfaces, 3 (2019) 25. 